\title{
1864. El asalto a la razón de Dostoievski
}

\author{
1864. Dostoevsky's Destruction of Reason
}

DAVID MONTERO BOSCH*

Resumen: El presente artículo es un intento de situar en su contexto el pensamiento anti-nihilista de Dostoievski. Se centra en la reacción del autor ruso contra su contemporáneo Chernishevski, que se origina entre 1861 y 1864. Las novelas de este periodo son habitualmente consideradas el punto de inflexión hacia la madurez y focalizan su reflexión en temas filosóficos. Aquí se ha escogido especialmente el de la oposición de Dostoievski al positivismo de Chernishevski, que éste formulaba en términos utilitaristas o del egoísmo inteligente. Los autores contemporáneos que se han ocupado del tema han evaluado los argumentos de Dostoievski desde una clara simpatía con su oposición al radicalismo revolucionario o al positivismo. En esta línea se adopta habitualmente una separación entre sus escritos teóricos y las novelas. Este trabajo, por el contrario, pretende presentar los argumentos los dos autores rusos desde una perspectiva más neutra. Desde este punto de vista se ha tratado de buscar las conexiones del proyecto literario de Dostoievski con su pensamiento político y religioso que desembocan en lo que se ha llamado aquí el "asalto a la razón".

Palabras clave: Dostoievski, Chernishevski, irracionalismo, egoísmo inteligente, utilitarismo, nihilismo.

\begin{abstract}
This article is an attempt to locate the anti-nihilist thought of Dostoevsky in its real context. It focuses on the reaction of the Russian author against his contemporary Chernyshevsky, which has its beginning between 1861 and 1864 . The novels of this period are usually considered the turning point towards maturity and focus their reflections on some philosophical topics. Dostoevsky's opposition to Chernyshevsky's positivism, based on utilitarianism and intelligent egoism, has been chosen here. The contemporary authors have evaluated Dostoevsky's thesis from a clear sympathy for his position against revolutionary radicalism or positivism. This line usually makes a gap between the theoretical writings and novels. However, this article aims to present the arguments of the two Russian authors from a more neutral perspective. From this point of view the aim has been the connections between Dostoevsky's literary project and his political and religious thought that leads to what is called here the "destruction of reason".
\end{abstract}

Keywords: Dostoevsky, Chernyshevsky, irrationalism, intelligent egoism, utilitarianism, nihilism.

En Abril de 1849 un alto dignatario ruso, el Senador K.N. Lebédev, escribe en su diario: "Toda la ciudad está preocupada con la detención de algunos jóvenes (Petrashevski, Golovinski, Dostoievski, Palm, Lamanski, Grigóriev, Mijáilov y otros muchos)"'1. Lebédev

Fecha de recepción: 01/12/2014. Fecha de aceptación: 16/07/2015.

* Universidad de Valencia. Doctorando. damontero22@hotmail.es. Publicación relacionada: "La dialéctica entre fuerza y debilidad en Dostoievski (1860-64). La ideología como clave para la interpretación", Revista de Filosofía (Madrid) 38 (2):135-147 (2013). Líneas de trabajo: emociones morales, Dostoievski, Albert Camus.

1 Frank, Joseph, Dostoevsky. The Years of Ordeal. 1850-1859. Princeton University Press, 1990, p. 6. 
consigna también que estos jóvenes se reunían en casa de Petrashevski, bajo el pretexto de encuentros literarios, para discursear acerca de la cuestión campesina, la reforma del gobierno o los desórdenes que ocurrían en Europa Occidental.

Tales actividades llevaron a la detención de los miembros de la supuesta organización y a un proceso en el que se dictaron severas condenas que incluían la pena de muerte para los que fueron considerados cabecillas, entre los que se encontraba Dostoievski. Después de un simulacro de fusilamiento, la pena capital se conmutó por una sentencia a trabajos forzados y exilio en Siberia, que en el caso de Dostoievski, duró ocho años².

La pieza de convicción principal que figuraba en la acusación contra él fue el hecho de que hubiera leído en una de las reuniones una carta abierta que el crítico radical Belinski había dirigido contra el novelista Gógol. Éste, que había significado en su momento un modelo para los radicales, había proclamado en un artículo que la única esperanza del pueblo ruso era la muy conservadora iglesia ortodoxa. En la carta que Dostoievski leyó, al parecer con fuerza y emoción, según un esbirro infiltrado, se proclamaba una especie de manifiesto ilustrado y radical en el que se podía leer:

Por lo tanto, Ud. no se ha dado cuenta de que Rusia ve su salvación no en el misticismo, ni el ascetismo, ni en la piedad, sino en los logros de la civilización, la iluminación y la humanidad ${ }^{3}$.

Aparte de su sentido explícito, esta carta contenía algunas referencias que apuntaban hacia el movimiento socialista de inspiración cristiana a la manera de George Sand y, más allá, al fourierismo, un movimiento muy de moda entre la intelligentsia rusa de aquellos momentos. No sorprenden demasiado en Dostoievski, quién en los momentos de idilio con el grupo de Belinski, en 1849 ya reducidos a cenizas, había expresado sus simpatías en este sentido. Ni siquiera en el escrito de exculpación que debió dirigir al tribunal durante el proceso, en el que trataba de desligarse del movimiento socialista, encontramos un rechazo absoluto a estos ideales que, justamente, serían para él ideas bellas, pero alejadas del contacto con el mundo real y sobre todo del pueblo ruso ${ }^{4}$.

El hiato entre el ideal ilustrado progresista manifestado en la carta de Belinski y el pensamiento de Dostoievski comenzará a ahondarse en los años subsiguientes a su regreso de Siberia hasta convertirse en una franca incompatibilidad, en la medida en que sus posiciones se fueron acercando a las concepciones tradicionalistas del partido eslavófilo. Ya en La aldea de Stepánchikovo y sus habitantes (1859), el peso satírico recae sobre el personaje de Fomá Fomich Opiskin, cuyos intentos de ilustración forzada del campesinado conducen a mil desastres más o menos chuscos. En pocos años, esta mirada cargada de ironía un tanto condescendiente se transformará en un ácido sarcasmo. De ser simplemente un iluso o un estúpido, el ilustrado progresista pasará a convertirse en el padre de todos los demonios desencadenados para la perdición del pueblo ruso: nihilistas, revolucionarios, ateos...,

2 Ibíd, cap. II, para los detalles del juicio y condena.

3 Belinski (Belinsky), Vissarion G., "Letter to N. V. Gogol", Selected Philosophical Works, Moscow, Foreign Languages Publishing House. 1948; p. 504-6. Traducción personal del inglés.

4 "Explication de F. M. Dostoïevski", en Catteau, dir., Cahier Dostö̈evski, Paris, Ed. de L'Herne, Cahiers de L'Herne, no 24,1974 , p. 33ss. 
denominaciones bajo las que se englobaba a todos aquellos que se oponían radicalmente a la política y la moral dominantes. Por el camino, la invocación a los "logros de la iluminación" que figuraba en la carta de Belinski quedará absolutamente olvidada. Años más tarde escribe desde el lado opuesto: "Yo afirmo que nuestro pueblo se ha ilustrado ya hace tiempo al recibir en su esencia a Cristo y sus enseñanzas"5.

Por lo que sabemos de sus propias declaraciones y las de sus allegados, el compromiso de Dostoievski con los ideales revolucionarios fue efímero y atormentado. Desde el momento de su encarcelamiento en Siberia hasta su regreso a la actividad literaria y social en 1860, se había producido un giro de $180^{\circ}$ en su pensamiento. Por una parte, este cambio se traduce en un creciente alineamiento con el tradicionalismo eslavófilo, basado en su caso en una especie de adhesión emotiva al zar como persona y símbolo del alma del pueblo ruso, verdadero ejemplo del cumplimiento del designio divino a escala universal. Por otro lado, Dostoievski se siente tocado por el dedo de Cristo en forma de crisis, al parecer de índole epiléptica, que le permiten la experiencia de un sentimiento de felicidad inefable que él asocia con el Amor a todo y todos ${ }^{6}$. No se trata aquí de abrir el debate en torno a la naturaleza de la enfermedad de Dostoievski, sino señalar tan sólo cómo, en la explicación que él mismo da de su conversión, los instantes de éxtasis que preceden al abatimiento propio de estos casos le proporcionan un modelo que tratará de aplicar a las cuestiones de moral personal y política.

El resultado de este giro en el tema que nos ocupa, el de la crítica al racionalismo, se puede observar en la carta que, poco después de salir del presidio, escribe a una de sus benefactoras, la Sra. Fonvizina, esposa de uno de los famosos decembristas.

Creo que no hay nada más hermoso, más profundo, más atractivo, más racional, más humano y más perfecto que el Salvador; me digo a mí mismo con amor celoso que no sólo no hay nadie como Él, sino que no puede haberlo. Incluso me atrevería a decir más: si alguien pudiera probarme que Cristo está fuera de la verdad, y si la verdad realmente excluye a Cristo, yo preferiría quedarme con Cristo y no con la verdad ${ }^{7}$.

Algunos críticos han intentado suavizar el irracionalismo de sentencias como la anterior restringiendo su alcance. Según ellos, Dostoievski no estaría condenando la razón y la ciencia, sino un determinado tipo (positivista) de entenderlas ${ }^{8}$. En mi opinión, sólo una descontextualización permite este tipo de suavizaciones. Considerado en su contexto, el párrafo se deja entender como una pieza más de un proyecto típicamente fideísta.

5 Dostoievski, Fiódor, "Disputa al caso. Cuatro lecciones sobre diversos temas a propósito de una lección que de dictó el Sr. Gradovsky. Con una invocación al Sr. Gradovsky", en Páginas críticas del "Diario de un escritor”, Buenos Aires, EMECÉ, 1944, p. 52.

6 Frank, Joseph, op. cit., p. 196.

7 Carta a la Sra. Fonvizina (20 febrero 1854; (Ethel G. Mayne, trad y ed.,: Letters of Fyodor Michailovitch Dostoevsky to his Family and Friends, London, Chatto \& Windus, 1917, $2^{\text {a }}$ edición, p. 66). Aforismo al que recurre Dostoievski a lo largo de su vida. En la versión de Catteau (Fiodor Dostoïevski: Correspondance T. 1; Jacques Catteau ed., Paris, Editions Bartillat, 1998, p. 341), la expresión "realmente" está resaltada. Posteriormente encuentra un tratamiento mucho más explícito en palabras de Shátov, que en Los demonios (1869) claramente habla por Dostoievski (Dostoievski, F. Los demonios, Madrid, Alianza Editorial, 1984, p. 299).

8 Katz, Michael R.: "Dostoevsky and Natural Science" en Dostoevsky Studies, vol 9, Universidad de Tornonto, 1988 , p. 74. 
No quiero decir con ello que el proyecto vital y literario de Dostoievski sea un fideísmo cerrado, como el del movimiento eslavófilo de su tiempo. Los principios o ideas que rigen el proyecto intelectual del novelista se desarrollan de manera dialéctica en la confrontación con las teorías rivales. Es un mérito comúnmente reconocido al crítico ruso Mijaíl Bajtín el haber señalado la naturaleza polifónica de la obra de Dostoievski, esto es, la característica esencial de los personajes dostoievskianos consistente en encarnarse como ideas vivas en una continua oposición de puntos de vista conflictivos. Esta tensión se manifestaría tanto en la confrontación con actantes diversos cuanto en la formación misma de su discurso interno9. Sin embargo, en mi opinión, Bajtín confunde lo que es una técnica expositiva y persuasiva, la polifonía, con el proceso de desarrollo del proyecto novelístico. En cierto sentido, se puede decir que el autor lleva a cabo en la novela un proceso de experimentación de sus creencias, confrontando su resistencia o poder respecto a otras que mantienen principios contrarios a las suyas. Este proceso puede ser más o menos objetivo, más o menos inteligente o más o menos consciente, pero siempre se da en la trastienda de la obra literaria. Dostoievski, a diferencia de otros autores contemporáneos que ocultan el bullir de la lucha de contrarios en la gestación y presentan el producto final de forma monolítica y cerrada, levanta el velo y deja que la confrontación se manifieste públicamente. Es más, convierte el principio de ideación literario en antropológico cuando entra en la mente de sus protagonistas y expone esta misma lucha como parte de su personalidad. Pero no hay que perder de vista que este procedimiento corresponde a un intento de exposición persuasiva ${ }^{10}$.

A partir de 1864, el referente que sirve para puntuar el desarrollo de las novelas de Dostoievski, el leitmotiv de los conflictos internos y externos de sus protagonistas, es el nihilismo, especialmente encarnado en Nicolái Gavrílovich Chernishevski, el principal mentor de la radicalidad rusa a principios de los años 60 del siglo XIX ${ }^{11}$.

Admiradores de Dostoievski, como Berdiaeff, Catteau o Camus ${ }^{12}$, asocian su ácida crítica al nihilismo a la prevención contra los sistemas socialistas autoritarios. Pero una parte importante del movimiento socialista ruso de 1860 era contraria a estas formas de oposición al zarismo. Chernishevski abogaba por un socialismo democrático y había desautorizado los pronunciamientos a favor de la violencia indiscriminada. Para él, ninguna coacción puede dar lugar al bien. La justicia sólo puede alcanzarse liberando la naturaleza humana de todos los instrumentos de la opresión y el adoctrinamiento, mediante el convencimiento racional. A favor de un tránsito pacífico al socialismo democrático también se había manifestado Petras-

9 Bakhtin, Mikhail, Problems of Dostoevsky's Poetics, Minneapolis, University of Minnesota Press, $8^{\mathrm{a}}$ edición, 1999 , p. 92.

10 Una crítica similar en Wellek, René, "Bakhtin's View of Dostoevsky: 'Polyphony' and 'Carnivalesque'”, en Dostoevsky Studies, Toronto, International Dostoevsky Society, Vol 1, 1980, p. 33.

11 Para la confrontación que Dostoievski lleva a cabo con su obra, en concreto su novela ¿Qué hacer?, cf. Llinares, Joan B., "La crítica de F. Dostoievski a la antropología de N. Chernishevski. Memorias del subsuelo como réplica ¿ ¿Qué hacer?”, VIII Congreso Internacional de Antropología Filosófica 'Las dimensiones de la vida humana' - Madrid, UNED, 16-19 de septiembre de 2008, SHAF.

12 Berdiaeff, Nicolás, El credo de Dostoyevsky, Barcelona, Apolo,1935, p. 20; Catteau, Jacques: «Du palais de cristal à l'âge d'or ou les avatars de l'utopie», en Catteau, Jacques, dir., Cahier Dostoïevski, Paris, Ed. de L'Herne, Cahiers de L'Herne, no 24, 1974, p. 184; Camus, Albert, "Pour Dostö̈evsky", en. Jacqueline LéviValensi, ed,, Albert Camus.CEuvres complètes, IV, 2006, p. 590. (Original de 1958). 
hevski, en oposición a algunos miembros más radicales del grupo que recibió su nombre, entre los que algunos autores sospechan que pudiera haber estado el propio Dostoievski ${ }^{13}$.

Pero al escribir en 1864 Memorias del subsuelo, la primera de sus diatribas noveladas contra el movimiento renovador en Rusia y su ala radical, las críticas de Dostoievski no van en la dirección que mencionan Camus o Catteau. No tratan de la violencia como arma política. En este momento, se dirige más bien a la crítica del racionalismo utilitarista o, más ampliamente, de la razón ilustrada como fundamento de un sistema social justo e igualitario que correspondería grosso modo al socialismo utópico. Y en este momento, 1864, Chernishevski ha escrito en la cárcel una novela panfleto que había de conmocionar el universo político ruso, Una pregunta vital, o ¿Qué hacer? ${ }^{14}$.

Uno de los aspectos de esta novela que más atractivo ejerció sobre el radicalismo ruso y más escandalizó a la intelectualidad conservadora y liberal fue el rechazo a la moral, hasta el punto de que éste se convirtió en el rasgo distintivo del nihilista. El movimiento radical socialista ruso no era un todo coherente. Las diferencias entre unos y otros sectores podían ser sustanciales, pero a partir de la novela Padres e hijos de Turguénev (1862), se acuña el término "nihilista" para atribuirles un rasgo común distintivo ${ }^{15}$. Consistiría éste en un cierto inmoralismo, es decir, la supeditación de la moral al pensamiento positivo o a la eficacia revolucionaria. Característicamente, uno de los protagonistas de la novela de Chernishevski, Lopújov, se niega en redondo a emitir cualquier juicio moral, incluso sobre los personajes más repelentes que se cruzan en su camino. En su opinión, que obviamente expresa la del autor, las personas actúan impulsadas por fuerzas determinantes y por su ignorancia respecto a lo que realmente les conviene. Condenarlas por acciones a las que están necesariamente abocadas, debidas a la educación y a la naturaleza de sus impulsos biológicos, sería como condenar a la piedra que cae por una pendiente por los daños que pueda causar. De igual manera, cuando se tiene en cuenta que el libre albedrío es una ilusión, se apercibe uno de que los actos que más nos repugnan están provocados por la ignorancia de los verdaderos intereses de la persona malvada, ignorancia de la que ella no es responsable. Según el aforismo hegeliano, todo lo real es racional y ocurre porque debe ser según ley. Por lo tanto, ignorar la ley es absurdo. Lo que hay hacer es utilizarla racionalmente. Hay que poner los medios para que el entorno social no produzca individuos asociales y perversos. Esto se consigue mediante la transformación de la sociedad y mediante la persuasión racional. Así, la fuerza dialéctica de Lopújov llega a convencer de manera natural a una madre despiadada que trata de explotar a su hija de que sus verdaderos intereses están en dejar que ésta escape a sus designios siguiendo su propio camino. Nada es imposible para quién, olvidándose de las inútiles exhortaciones a los grandes principios morales y con lógica implacable, convence de que la propia felicidad consiste en la cooperación y el respeto mutuo.

La noción del egoísmo racional de Chernishevski constituía un intento de formular una teoría del bien natural compatible con una epistemología positivista y una ontología materialista. La ciencia constituye el único método que provee de conocimiento al hombre. Es más, es capaz de proporcionar un conocimiento exacto de la naturaleza material de las

13 Venturi, Franco, El populismo ruso, t. 1, Madrid, Alianza Editorial. 1981, pp. 26-7, 213.

14 Tchernishevsky, Nicolai G., A Vital Question or What Is to Be Done ?, New York, Thomas Y. Cromwel, 1898.

15 Turguénev, Iván S., Padres e hijos, Madrid, Cátedra, 2ª ed, 2002. 
cosas, la única realmente existente. Obviamente, ese conocimiento no es dado de una vez por todas, sino adquirido mediante un proceso progresivo en el que el hombre va desarrollando medios cada vez más potentes, no sólo de comprensión, sino de control tecnológico de los recursos naturales. En ¿Qué hacer?, las teorías políticas de Chernishevski se transforman en una utopía visionaria futurista y esencialmente optimista. La novela tiene dos desarrollos paralelos. Uno está dedicado a reflejar la lucha de los precursores, apóstoles del egoísmo racional, que en aquellas fechas eran relacionados con el nihilismo, como el caso de Lopújov que he mencionado antes. Otra parte son los sueños de la protagonista, en los que se describe una sociedad futura regida por los principios de utilidad y cooperación.

Por lo tanto, eliminando la moral autónoma, la metafísica, la religión y todas las construcciones ideológicas que fundamentan el malestar de los pueblos, la filosofía materialista contribuye al progreso de la única manera eficazmente posible: mediante la aplicación de los principios científicos al conjunto de la vida social y personal de los hombres. La nueva filosofía no hace sino señalar cuáles son esos principios de la verdadera felicidad y cómo llevarlos a la práctica.

Dostoievski reaccionó violentamente contra este positivismo, aunque en ningún caso realizó una evaluación analítica del aparato conceptual de Chernishevski, quizás lo más discutible de la concepción positivista de este último. Su estrategia -la de Dostoievski-, como se verá hacia el final de este trabajo, consiste en dejar abierta la posibilidad de algún tipo de fundamentación de las creencias que sea superior a la racionalidad. Su argumentación empieza por rebajar la jerarquía cognoscitiva de la razón en general y la ciencia, en particular, con el fin de enfrentarla a una certeza de orden superior de orden espiritual.

En Notas de invierno sobre impresiones del verano, dedica un contundente párrafo al asunto.

¿Los argumentos de la razón pura? Pero la razón se ha revelado inconsistente delante de la realidad y, lo que es más, los mismos hombres dotados de razón, los mismos sabios, hoy comienzan a profesar la idea de que los argumentos de la razón pura no existen, que la razón pura misma no existe, que la lógica abstracta es inaplicable al hombre, que lo que existe es la razón de los Iván, los Pedro y los Gustavo, y que la razón pura en sí misma no ha existido nunca : es solamente una invención inconsistente del siglo XVIII' ${ }^{16}$.

Verdaderamente el párrafo es demasiado breve y su estilo condensado no permite siquiera aclarar el concepto de "razón pura" que aquí se maneja. No parece que con el término razón pura se esté refiriendo al concepto kantiano. En el marco de las polémicas filosóficas y literarias en la Rusia de mediados del XIX, los referentes son más bien el hegelianismo y el positivismo, conocidos generalmente a través de epígonos o derivados. Creo que decir que "la razón pura no existe" es una manera de rebatir la confianza absoluta que Chernishevski mostraba respecto a los principios y métodos de la ciencia. Cuando Dostoievski afirma, en las notas que escribe en el velatorio de su primera mujer, que existe una "confusión e

16 Dostoïevski, Fiodor, Notes d'hiver sur impressions d'été, Arles, Actes du Sud, 1995, p. 87. Traducción personal del francés. 
incertidumbre en los principios" que es debida a que "el estudio racional de la naturaleza es demasiado joven", y cita a Descartes y Bacon, es obvio que está pensando en la Nueva Ciencia como modelo de racionalidad ${ }^{17}$.

Pero en el siglo XIX, negar a la ciencia la capacidad de obtener conocimiento es realmente difícil. Ni la razón de Pedro ni la de Iván han conseguido construir puentes o precisar los movimientos de la Tierra, y algún tipo de conocimiento se desprende de esta clase de hechos. Dostoievski es consciente de la dificultad de un relativismo absoluto, pero trata de soslayarlo reduciendo la ciencia a un saber de segundo orden. Concede que la ciencia sería útil como un saber instrumental, pero que jamás podrá constituirse como saber sobre el ser humano ${ }^{18}$. Podemos agradecer a la ciencia occidental aquellos conocimientos que nos permiten vivir más cómodamente, pero hallar en la razón cualquier contribución a la búsqueda de una guía que de sentido a la vida, esto es sencillamente imposible. Aparentemente Dostoievski plantea aquí el problema del intelecto y el sentimiento moral. En realidad se trata de colocar por delante de la razón cualquier tipo de motivación humana que sea diferente y más poderosa: las emociones, el deseo de libertad o, en el extremo, el impulso irrefrenable hacia el mal. En este camino podría haber encontrado algunos antecedentes en los propios ilustrados. Pero el que emprende Dostoievski es peculiar y le aleja de cualquier forma de Ilustración, incluso de los disidentes del racionalismo extremo. Él opondrá a la razón no sólo los sentimientos, sino los impulsos agresivos o la fe religiosa en su acepción más clásica, porque todos ellos minan, de alguna manera, el poderío que Chernishevski había atribuido a la razón, su imperio sobre los mandatos morales. Por eso, desde el punto de vista psicológico o antropológico, como fundamento de la conducta humana, Dostoievski opone las emociones y el deseo de libertad a la razón.

La base de la teoría del egoísmo inteligente de Chernishevski era una afirmación fáctica: los seres humanos siempre tienden a buscar el fin que, de acuerdo con su capacidad para la racionalidad, consideran que más les conviene. Él pensaba que se podía hacer un listado de impulsos básicos, que siempre serían dominantes en cualquier conflicto y también que estos impulsos podían hacerse patentes mediante un libre debate, permitiendo a las personas conocerse mejor y saber cuáles podían ser los medios más adecuados para su felicidad. Podríamos decir que estos dos principios marcan su optimismo respecto a las posibilidades de progreso social. Pese a las dificultades inherentes a la obstrucción de los poderes conservadores, la mejora de la sociedad es posible mediante el esfuerzo racionalizador, basado en las potencialidades de la naturaleza humana.

Frente al optimismo antropológico de Chernishevski, Dostoievski se manifiesta contrario a cualquier teoría explicativa sobre la naturaleza humana. La piscología como ciencia es imposible porque el ser humano es esencialmente impredecible. A lo largo de toda su obra literaria, Dostoievski muestra los aspectos más inestables de la conducta de sus personajes, que se ven arrastrados por fuerzas ocultas que, ni ellos ni el lector, pueden prever. Si podemos decir que la conducta normalizada consiste en fijarse objetivos y medios coherentes, los antihéroes dostoievskianos llevan su patología hasta hacer todo lo contrario de lo que

17 "Méditation devant le corps de Marie Dmitrievna", en J. Catteau dir., Cahier Dostö̈evski, Paris, Ed. de L'Herne, Cahiers de L’Herne, $\mathrm{n}^{\circ}$ 24, 1974.

18 Dostoievski, Fiódor, "Disputa al caso.", Op. Cit., p. 51 y Dostoievski, Fiódor, Diario de un escritor, Barcelona, Alba Editorial, 2007, p. 305, respectivamente. 
piensan, sumiéndose en estados de estupor cuando menos les conviene y apasionándose de tal manera que pierden todo sentido de la realidad. Una y otra vez, los personajes se ven forzados a situaciones ridículas o dramáticas, cuyo caso más paradigmático es el empeño de Raskólnikov (Crimen y castigo), por hacer y decir todo lo que le incrimina sin poder evitarlo. Por otra parte, en la descripción de estos estados y conductas anormales Dostoievski juega constantemente con predicados incompatibles entre sí, no sólo en estadios inmediatamente sucesivos, sino simultáneamente. Esta anti-psicología, que tanto molestó a Belinski, es una reacción directa contra el principio de utilidad de Chernishevski.

Llevada a su extremo, la incoherencia psicológica liberaría impulsos destructivos, un sadismo básico que sería un componente de la naturaleza humana más dominante que cualquier otro. En el caso del Mayor, el terrorífico director de la prisión en Memorias de la casa muerta, el sadismo es puro instinto de crueldad. Algo semejante en el caso de Cleopatra (Memorias del subsuelo) -personaje que toma de Pushkin, adaptándolo a su manera-, a la que el mortal aburrimiento de una vida satisfecha lleva a las más refinadas crueldades. Nada que hacer con estos individuos (más numerosos de lo que querría Chernishevsky), cuyas inclinaciones desmienten la idea de que se puede convencer al malo mediante la argumentación racional. Dostoievski emplea este componente perverso de la humanidad para rechazar la utopía de Chernishevski como inviable. El arquetipo es el dandy conservador que el Hombre del Subsuelo imagina, que antepone su libertad arbitraria para destruir la felicidad reglada y colectiva porque ésta le resulta insufrible: "Bueno señores ¿y por qué no echamos de una vez abajo esa cordura, para que todos esos logaritmos se vayan al demonio y finalmente podamos vivir conforme a nuestra absurda voluntad?"19.

Es esta una figura inquietante, tremendamente ambigua. Casi parece que Dostoievski justifica este tipo antisocial que coloca su capricho por encima de los beneficios sociales en nombre de la superioridad de la libertad sobre la razón. En otra de las posibles interpretaciones, el dandy simboliza los impulsos egoístas que resistirían a todo intento de persuasión racional, sin más base que la negación de todo consenso. Que Dostoievski refleje correctamente el punto de vista de Chernishevski es asunto diferente. Aquí, por ejemplo, Chernishevski había previsto la objeción de la existencia de elementos asociales similares al “caballero reaccionario". Para prevenirla, establece una especie de ostracismo, según el cual, quien no estuviera dispuesto a seguir las normas de la colectividad ideal podría irse a vivir fuera de ella, en una sociedad no cooperativa en la que desfogar sus impulsos destructivos particulares. La solución, buena o mala -y habría que recordar Brave New World de Aldous Huxley para contemplarla con más profundidad ${ }^{20}-$, no cogía desprevenido a Chernishevski.

Junto con la eclosión de los instintos perversos de la naturaleza humana, Dostoievski recurre a un argumento típico del pensamiento conservador: establecer la absoluta incompatibilidad entre la justicia igualitaria y la libertad, fundándola en la índole de la naturaleza humana.

19 Memorias del subsuelo, Madrid, Cátedra, $5^{\text {a }}$ ed., 2009, p. 90.

20 En Brave New World (Un mundo feliz, Barcelona, Plaza y Janés, 2000), Aldous Huxley satiriza amargamente sobre la exclusión de los elementos antisociales que son encerrados en una reserva de "salvajes". 
Pero entonces, nuevo enigma: a priori, se asegura al hombre plenamente, se le promete nutrirlo, darle de beber, proporcionarle trabajo, y, a cambio, no se le pide más que una muy pequeña gota de su libertad personal por el bien de todos, la más pequeña, la más minúscula. No, el hombre se niega a vivir con todos estos cálculos, incluso ceder esa gota es doloroso para él. Él muy imbécil, siente que está en una cárcel, y es mejor estar solo, porque entonces, él tiene libertad total. (... $)^{21}$.

Pero nótese que lo que hace Dostoievski es oponer la absoluta libertad a cualquier grado de justicia social. No se trata de los límites intolerables a la libertad que se establecen en éste o aquél sistema autocrático o totalitario, sino de ceder "una gota" de libertad. Y nótese también que Dostoievski aparenta no estar haciendo una valoración, sino enunciando un hecho propio del "ser hombre". El hábil uso de la ironía -“el muy imbécil", equivalente aquí al "sí que lo siento"- hace recaer el peso del argumento en el ser así de lo humano. El socialismo queda refutado en este primer intento por su insuficiencia para contentar el impulso irrefrenable a la libertad. No cualquier libertad, sino la libertad absoluta. Pero entonces, Dostoievski está destruyendo toda posibilidad de una sociedad mantenida sobre un contrato porque el mismo hecho de establecer uno, sea el que sea, implica la renuncia a "una gota" de libertad. Y esto no es porque el contrato sea malo, dice, es que es imposible. Cualquier atisbo de democratización llevaría al caos hobbesiano, y la alternativa inmediata -de la utópica hablaré hacia el final- no es otra sino la autocracia paternalista del Zar, a quien dedicó Dostoievski algunos ditirambos apasionados ya desde su salida de la prisión ${ }^{22}$.

Pero, una vez la caja de Pandora abierta, no sólo deja escapar la agresividad innata contra personas y cosas, sino la tendencia hacia la autodestrucción. El héroe trágico asumía el sufrimiento porque era la consecuencia natural de su orgullo. Orgullo de realeza, como en Edipo; orgullo de valor, como en Aquiles; orgullo de mujer ultrajada, como Medea... Orgullo de hombre-dios, cuyo destino en las novelas de Dostoievski no puede ser otro que el suicidio que espera a todo endemoniado consciente. Pero si los antihéroes dostoievskianos, dominados por el orgullo de equipararse a Dios, están abocados a la autodestrucción deliberada, tampoco hay el menor rastro de búsqueda del propio interés en los héroes positivos, sino la felicidad o resignación en el sufrimiento y la humillación propios. El protagonista dostoievskiano, se caracteriza por la asunción de su sufrimiento como una condición de salvación, previa toda renuncia a mantener una posición de poder o de exaltación de la felicidad de vivir con placer. Natasha (Humillados y ofendidos) plantea el tema directamente: "Es necesario sufrir otra vez de algún modo por nuestra futura felicidad, comprarla a costa de nuevos tormentos. El sufrimiento lo purifica todo..."23. El concepto de la naturaleza humana es así esencialmente trágico. No parece posible una alternativa de felicidad consecuente con los principios del placer, sino que la consciencia desemboca necesariamente en la autodestrucción o el sufrimiento.

21 Dostö̈evski, Notes d'hiver sur impressions d'été, op. cit., pp. 94-5.

22 Empenzando por el poema que dedica a la zarina viuda de Nicolás I (Frank, op. cit., p. 199). Dejo de lado la cuestión de si también aquí Dostoievski refleja adecuadamente el pensamiento de Chernishevski. En mi opinión vuelve a simplificarlo en exceso. Parece que el concepto de "gallinero", que es el que utiliza despreciativamente Dostoievski en Memorias del subsuelo, convendría más a las visiones de Písarev.

23 Dostoievski, Fiódor, Humillados y ofendidos, Madrid, Boreal, 1998. p. 90. 
Como dije más arriba, dentro del campo del racionalismo y la Ilustración es posible encontrar ejemplos de pensadores que hayan advertido sobre los límites morales de la racionalidad. Spinoza y Diderot llamaron la atención sobre el poderío de las emociones; Hume, sobre la incapacidad de la razón para fundamentar los juicios de valor; Rousseau, sobre los peligros de los artificios racionales desvinculados del sentimiento moral. Aunque Dostoievski se acerca bastante a este último, da unos cuántos pasos más en la condena de la racionalidad y la inteligencia: es el ejercicio mismo de la razón el que destruye la bondad. Este camino de autoaniquilación se ejemplifica de manera señalada en la tercera de las novelas que Dostoievski publica tras su retorno a Petersburgo, Memorias del subsuelo.

Memorias del subsuelo es el eje en el que se consuma el giro del pensamiento de Dostoievski contra el racionalismo. Su protagonista es el primero entre los anti-héroes dostoievskianos en ejemplificar claramente la tensión entre la razón y la emoción, que en este caso se resuelve en la derrota de la segunda en la escena final de la novela. La razón no es sólo impotente frente a los sentimientos humanos, como ante el caso del egocéntrico irremediable o del sádico compulsivo, sino contraria a las motivaciones positivas como la empatía. En efecto, en el caso del Hombre del Subsuelo, en donde eclosiona el problema de una forma explícita, mientras que el deseo es la fuente de las emociones positivas (el amor), la razón es la que se le opone con el cálculo egoísta del propio interés. En el momento cumbre de la segunda parte, cuando el afán de humillar hace que el protagonista ponga en la mano de Liza un billete de cinco rublos después de violarla -o intentarlo-, su consciencia implacable nos informa de algo que, por otra parte, ya venía anunciado varias veces: “... no lo hice sintiéndolo con el corazón, sino por culpa de mi estúpida cabeza. Aquella crueldad resultaba tan fingida, tan cerebral, tan premeditada y elaborada..."24.

El Hombre del Subsuelo inicia la galería de individuos atormentados por la contradicción entre razón y sentimiento que llega hasta Iván Karamázov y cuyo representante más elaborado es Stavroguin en Los demonios. Dostoievski explota en todos ellos el drama de la persona incapaz de amar, muy típica del melodrama de todas las épocas, para conseguir dar tensión a un problema que, en el fondo, es filosófico. No es el único que recurre a este artificio literario para plantear el tema. Por las fechas en que Dostoievski comienza a escribir tras el exilio, se publica una de las novelas más emblemáticas de Turguénev, Padres e hijos, que muestra el mismo dilema en la persona de Bazárov, el nihilista. El esquema es el mismo: el intento de racionalizar la conducta en base al principio de utilidad lleva necesariamente a la destrucción de la persona porque en la búsqueda del bien el sentimiento es superior a la razón y la razón embota la capacidad de sentir. Su ciencia, la medicina, destruye a Bazárov física y simbólicamente. Stavroguin, antes de suicidarse, arrastra a todas las personas de su entorno. Por su parte, el Hombre del Subsuelo prefiere enterrarse en vida. En cualquier caso, todos ellos ilustran la perversión de la racionalidad. Frente a los personajes diabólicos que, simplemente, carecen de toda empatía, como Stavroguin o Piotr Stepanovich Verhovenski (Los demonios), resultan mucho más patéticos los que deliberadamente embotan sus afectos debido a una constante racionalización de su conducta, como el Hombre del Subsuelo. Son ellos los que ejemplifican el exceso de la inteligencia, que se manifiesta de diferentes formas.

24 Dostoievski, Fíodor, Memorias del subsuelo, op. cit, p. 191. 
Uno de los efectos del dominio de la razón sobre los deseos es la inactividad. Si la razón demuestra que algo es, como que dos más dos son cuatro, establece un muro con el que mis deseos chocarán sin poder hacer nada por mucho que quiera, dice el Hombre del Subsuelo. Entonces, la razón elimina el deseo y lleva a la inactividad.

¡Hagan el favor! - les gritarán—, es inútil rebelarse. ¡Se trata, del dos por dos son cuatro! La Naturaleza no va a consultarlo con usted; poco le importan sus deseos, y si le gustan o no sus leyes. Deben aceptarla tal y como ella es, y por consiguiente, también aceptar todos sus resultados ${ }^{25}$.

También la motivación desaparece desde el momento en que la razón demuestra que no hay responsabilidad porque los hombres actúan determinados por causas ineludibles. Desde un punto de vista moral, el hombre está motivado a hacer determinadas cosas porque siente que es su obligación hacerlas. Si la idea de obligación desaparece, se llevaría con ella lo que consideramos el hacer propiamente humano. Un mundo sin obligaciones regresaría al mero animalismo en la conducta. No habría lugar para la civilización.

Estos dos argumentos, como todo el monólogo del Hombre del Subsuelo, están dirigidos contra Chernishevski, al que, una vez más, por mor de la eficacia dialéctica, se simplifica considerablemente. En la teoría de este último, la lógica del determinismo no lleva a la inacción. Por el contrario, como dije más arriba, una comprensión mejor de las leyes de la Naturaleza es la condición necesaria para poder utilizarlas en nuestro provecho. El desconocimiento de las mismas, lo mismo que el desconocimiento de la verdadera raíz de nuestras voliciones, es el que lleva al hombre a chocar contra lo que desconoce y caer en la desesperación ${ }^{26}$. No porque una persona deje de considerar moralmente buena la cooperación dejará de practicarla, si entiende que la satisfacción que de ella se extrae es superior al ejercicio del egoísmo desordenado. Lo que Dostoievski no advierte en sus críticas, ni Chernishevski probablemente tampoco, es que el determinismo de este último es imperfecto, es decir, introduce un elemento corrector que es la capacidad de comprensión. Sin la razón el determinismo es ciego; con la razón el hombre se capacita para utilizar la Naturaleza contra sí misma, por así decirlo. O si se quiere, servirá para ayudarla a que alcance un estadio más evolucionado. El acto civilizado inteligente no es más que el accionar de la Naturaleza por medios específicos. Las razones por las que la persona alcanza la comprensión de los hechos no están en su libre albedrío. No las elige, sino que se las encuentra. Pero en la medida en que le sobrevienen, por así decirlo, obligan a seguirlas. Al argumentar de esta manera, Chernishevski devuelve la consideración moral del problema al terreno de lo fáctico. El principio de conducta no sería un imperativo, sino el hecho de que cualquier persona que descubre cuál es su bien, si su constitución mental no está mermada, actuará persiguiendo ese bien. Y si su razonamiento es correcto, hará lo correcto. El caso del dandy asocial de Memorias del subsuelo planteará para el racionalismo egoísta una anomalía de la personalidad, no una conducta reglada ni un modelo de actuación para una persona sana.

25 Ibid., p. 79

26 "Essays on Gogol Period of Russian Literature", en N. G Chernishevski, op. cit., p. 490. (Trad. personal del inglés). 
Admitiendo esta precisión a la teoría del determinismo, el punto fuerte de la argumentación contra Chernishevski en el terreno de la psicología social habría que buscarlo en el personaje del príncipe Valkovski, en Humillados y ofendidos, obra escrita poco antes que las Memorias del subsuelo. Dado que esta novela no fue muy apreciada por el propio Dostoievski y que la crítica posterior no la consideró una de sus obras mayores, su importancia para entender la lucha que el autor mantuvo con Chernishevski ha sido menospreciada. Sin embargo, el personaje del villano Valkovski, constituía una refutación de la idea básica del utilitarismo progresista. La idea que transmite el personaje -y los personajes de Dostoievski son ideas encarnadas, como advirtió Bajtín ${ }^{27}$ - es que la persecución del propio interés asociada con una especial inteligencia desemboca en el cinismo, que utiliza a las personas para explotarlas. El cínico no actúa por dandismo, como el personaje de Memorias del subsuelo, cuyos impulsos le llevaban a la destrucción por la destrucción del orden social. Esto sería una patología desde el punto de vista del egoísmo racional. El príncipe Valkovski no destruye por el placer de hacerlo, sino que usa a las personas como herramientas de sus deseos. Él no podría satisfacerse con la autoexclusión reservada a los que no aceptan el orden reglado, como preveía la utopía de ¿Qué hacer?, porque su modo de existencia presupone la de otras personas (incluso su propio hijo) que puedan ser expoliadas y utilizadas en su propio interés en términos de riqueza y status social. En el cálculo de beneficios utiliza un baremo distinto y niega que la empatía produzca una satisfacción mayor o igual que la de sus deseos egoístas, entendidos estos en sentido individualista. La condición misma de la existencia del príncipe Valkovski es un sistema social basado en la cosificación, vale decir, la explotación de los seres humanos. Sus objetivos y sus medios son inteligentes y egoístas, pero sus consecuencias contradicen el bien solidario que pretendidamente debía resultar de su desarrollo lógico.

Abocado a este desafío, la vía del egoísmo racional cooperativo es complicada. O entrega la baremación y el cálculo de la felicidad en manos de psicólogos y etólogos, que tienen dificultades para establecer un consenso en estos puntos $-\mathrm{y}$ con ello se cuestiona el estricto positivismo-, o defiende la superior cualidad moral de la empatía sobre la búsqueda del mero provecho individual. Pero esta salida, al introducir lo cualitativo, le obliga a una labor alejada de las cuestiones de hecho y claramente marcada por los juicios de valor autónomos, que es lo que se quería evitar. Seguramente quién lea esto se habrá dado cuenta de que nos encontramos ante el clásico dilema de toda ética utilitarista.

Pero a lo largo de su obra Dostoievski apenas explota este filón. El nihilista oportunista, que utiliza su inteligencia para escalar en la jerarquía social y beneficiarse del poder económico, ya no vuelve a presentarse en sus novelas en el lugar preferente de Humillados y ofendidos. Vuelve a aparecer sin tanto protagonismo en Crimen y castigo, como el novio de Dunia Karamázov, Lujín, y luego se difumina aún más en las novelas siguientes. Es significativo que Dostoievski hubiera trazado uno de los retratos más vigorosos del nihilista de su tiempo, el del cínico triunfador, contra el que también arremeterá Tolstói en sus últimas obras, sin que, sin embargo, constituya el objeto de sus preocupaciones. Probablemente la diferencia entre ambos estriba en que para el autor de Resurrección el objetivo fundamental es

27 Bajtín, op. cit., pp. 24, 86...

Daimon. Revista Internacional de Filosofía, nº 68, 2016 
la crítica de la sociedad pseudocristiana de su tiempo, mientras que para el de Los demonios todos los males mayores derivan de los intentos nihilistas de destrucción del orden social.

Ahora se ha despejado el campo para la entrada de la transcendencia. Porque no cabe duda: si hay que elegir entre la Verdad y Cristo, Dostoievski descartaría la verdad, la razón o las pruebas contrarias a sus creencias. A la luz de lo dicho no creo que quepan muchas interpretaciones del párrafo de la carta a la Sra. Fonvizina que citaba al principio. La clave de la interpretación correcta de este texto reside, en mi opinión, en el concepto de razón que utiliza Chernishevski y que Dostoievski retoma sin modificarlo. En el contexto de este debate, la razón se equipara a la ciencia. Pero, en sintonía con los positivismos del siglo XIX, el concepto de ciencia aquí utilizado es dogmático. El radical ruso desdeña la característica esencial, o ideal, de la verdad científica, es decir, que se produce en un proceso de intercambio y consenso de hipótesis y teorías y en la revisión de los sistemas a la luz de nuevas experiencias y nuevos conjuntos teóricos. En cambio, Chernishevski habla de la razón (científica) como un bloque compacto de verdades que resultan ser inductiva o deductivamente inapelables. El desprecio con que despacha a las matemáticas no euclidianas, como juegos ociosos sin posibilidad de contacto con el mundo empírico, sin sentido ni referencia, ilustra de manera clara su punto de vista ${ }^{28}$.

Convertida la razón en un dogma, Dostoievski tiene a mano el recurso de oponerle otro dogma diferente, el de la fe. Paradójicamente, sus razones para preferir una antes que la otra también pueden ser utilitaristas. Según él, la superioridad de la fe sobre la razón reside en el hecho de que ésta es radicalmente anti-social. La lógica de los presupuestos racionalistas, como hemos visto, desemboca en las diferentes formas de nihilismo: el dandismo, la apatía, el crimen o el suicidio. Por tanto no es que la creencia en la inmortalidad del alma, principio en el que Dostoievski hace radicar la superioridad de la religiosidad sobre el ateísmo, se corresponda con los hechos o con las leyes de la racionalidad, sino que es, en sentido estricto, necesaria porque es útil o conveniente. La verdad, en el sentido en que Dostoievski la piensa, es superflua o perniciosa.

De qué manera y con qué fuerza se ejercen los beneficios de la fe es cuestión a la que Dostoievski respondió de manera ambigua. En sus obras teóricas la fe no es deseo ni volición, sino una fuerza misteriosa que impele a amar a toda la Humanidad a través de la figura de Cristo. En un texto no demasiado conocido, "Socialismo y Cristianismo", se explicitan claramente los supuestos del pensamiento antirracionalista de Dostoievski ${ }^{29}$. Aquí se construye en unos cuantos brochazos una utopía que oponer a la del egoísmo inteligente. El fin del Mal en la Tierra sólo podrá conseguirse cuando todo ser humano esté dominado, literalmente dominado, por el Amor a toda la Humanidad. Será el cumplimiento perfecto de la Regla Áurea, "ama al prójimo como a ti mismo". El proceso para llegar a tal punto utópico, que significaría el fin de la Historia, parte de oponer la libertad a la determinación y el individualismo al colectivismo, para, a continuación, ir renunciando a toda libertad y al Yo individual en una fusión universal del todo social. El Yo se aniquila libremente, y con ello se somete a la Ley del Amor, entregándose sin reservas a sus semejantes. Como todo el mundo se entrega a todo el mundo, éste es el Reino paradójico de la Individualidad sin indi-

28 Carta a sus hijos, 8 de marzo de 1878, en N. G. Chernishevski, op. cit., p. 518-9.

29 "Socialisme et Christianisme", en Catteau dir., op. cit., p. 63. 
viduos y la Libertad sin libertades. Este proceso no puede ser guiado por la inteligencia -ya lo hemos visto-, ni por la conciencia -si por tal se entiende algo autónomo-, sino por una "sensación invencible". Es ésta la misma sensación invencible de comunidad con el Todo que Dostoievski dice sentir en sus crisis nerviosas y que también reproduce literariamente en algunos pasajes de sus obras ${ }^{30}$.

De acuerdo con estas ideas, Dostoievski selecciona cuidadosamente los personajes de sus novelas poseídos por la fe o por el Amor, que son instancias equiparables. Todos ellos, desde el príncipe Mishkin, de El idiota, Aliosha Karamázov, Sonia Marmeladova, en Crimen y castigo, o ya de una manera muy directa el obispo Tijón (Los demonios) o el padre Zósima (Los hermanos Karamázov), muestran una penetrante perspicacia que no se deriva de sus cualidades intelectuales. La posición anti-intelectualista, expresamente declarada en los escritos teóricos, tiene su correlato en la valoración implícita de sus personajes literarios. Es Gide quién advierte que en los personajes positivos de Dostoievski, las almas buenas o los hombres santos, hay una carencia de o una renuncia a la inteligencia ${ }^{31}$. La bondad o la comprensión se asocian a impulsos e intuiciones, con frecuencia independientes u opuestos a la racionalidad e incluso al sentido común. En su extremo, el príncipe Mishkin puede parecer idiota porque sus discursos son considerados delirantes por los miembros de una sociedad encallecida por el racionalismo pragmático, pero demuestra ser enormemente persuasivo, lo mismo que Aliosha Karamázov, cuando habla a las almas simples, los niños. Algo parecido ocurre con Sonia (Crimen y castigo), cuya bondad evangélica irradia sin necesidad de decir palabra, encantando a los reclusos y empujando al arrepentimiento a Raskólnikof. Hay una Verdad que sólo es accesible a las almas simples, en consonancia con la interpretación habitual del conocido mensaje evangélico.

En el origen de todo ello está el Hombre del Subsuelo quien, con la agónica contradicción entre el sentimiento y la inteligencia y su hundimiento final en los sótanos del espíritu, marca el punto de inflexión en el que encontramos la primera denuncia de la causa primera de todos los males, según Dostoievski: el orgullo de la razón que se pretende autónoma. Construir una alternativa en forma de "idea encarnada", que diría Bajtín, fue la tarea de las novelas que le siguieron, pero los fundamentos ya estaban puestos en esta pequeña obra, que pasó casi desapercibida en su momento, pero que ha sido largamente recuperada y admirada a partir del siglo pasado.

\section{A modo de conclusión, ciertas implicaciones del caso}

No me gustaría haber dejado la impresión de que las claves de la polémica entre Chernishevski y Dostoievski -o más bien debería decir de Dostoievski contra Chernishevski- nos llevan a conceptos obsoletos de teorías que carecen de implicaciones con la actualidad.

Por un lado, si nos alejamos ligeramente del mundo académico, el utilitarismo de Chernishevski, que uno estaría tentado de apostillar como "vulgar", no difiere gran cosa de algunos representantes del cientificismo de nuestra época, como podría ser B. F. Skinner en

30 Una narración del propio Dostoievski en la que dramatiza sus éxtasis es "El mujik Maréi”, en Diario de un escritor, op. cit., pp. 201-7.

31 André Gide, Dostoïevski. Articles et causeries. Paris, Gallimard, 1970, p. 129. 
Más allá de la libertad y la dignidad, o más recientemente Sam Harris ${ }^{32}$. Y las posiciones irracionalistas cercanas a la de Dostoievski son muy fuertes en los mundos confusos de la política, la teología, la pseudociencia y las religiones de diseño.

Por otro lado, creo que, atendiendo a muchos aspectos concretos de su polémica, cuando alguno de los dos autores en los que me he centrado resulta ser más brillante -en lo cual, y al menos literariamente, Dostoievski lleva sobrada ventaja-, no es difícil encontrar el reflejo de sus ideas en la filosofía o la hermenéutica contemporáneas. Convenientemente expurgado de sus aspectos más reaccionarios, Dostoievski ha sido repetidamente citado por existencialistas o posmodernos, quienes parecen encontrar en él un terreno fértil en sugerencias ${ }^{33}$. El egoísmo inteligente de Chernishevski, también refinado, tiene puntos de contacto con el pensamiento contemporáneo que cifra la racionalidad en la satisfacción de los propios intereses $^{34}$. Y pienso que sería mal asunto si, llevados por nuestra cercanía sentimental o teórica a Dostoievski, descuidáramos evaluar a Chernishevski en su justa medida y con conocimiento de causa. Este artículo es un modesto intento de contribuir a esta labor.

32 Skinner, B. F., Beyond freedom and dignity. New York, Knopf, 1971. Harris, Sam, The Moral Landscape. How Science Can Determine Human Values. New York, Free Press, 2011.

33 Desde el karamazoviano "Si Dios ha muerto, todo está permitido", que recoge Sartre en El existencialismo es un humanismo (Buenos Aires, Huascar, 1972), hasta el prefacio de Julia Kristeva a La poétique de Dostö̈evsky de Mijaíl Bajtín (Paris, Ed. du Seuil, 1970). Sin olvidar los múltiples préstamos en toda la obra de Albert Camus.

34 Véase la armonización de auto-interés y justicia en la "posición original” en John Rawls, A Theory of Justice, Cambridge, Harvard University Press, 1999. También David Gauthier, Egoísmo, moralidad y sociedad liberal, Barcelona, Paidós, 1998. 
